\title{
Inhalation exposure to respirable particulate matter among workers in relation to their e-waste open burning activities in Buriram Province, Thailand
}

Sarasanant Bungadaeng ${ }^{1}$, Tassanee Prueksasit ${ }^{2,3^{*}}$ and Wattasit Siriwong ${ }^{4}$

\begin{abstract}
The mass concentrations of fine $\left(\mathrm{PM}_{2.5}\right)$ and coarse $\left(\mathrm{PM}_{2.5-10}\right)$ particulate matter were determined directly from breathing zones of e-waste dismantling workers during the primitive open burning processes using a Personal Modular Impactor connected to a personal air sampler. The average concentration of $\mathrm{PM}_{2.5-10}$ was $441 \pm 496 \mu \mathrm{g}$ $\mathrm{m}^{-3}(\mathrm{~N}=33)$, and for $\mathrm{PM}_{2.5}$, the average concentration was $2774 \pm 4713 \mu \mathrm{g} \mathrm{m}^{-3}(\mathrm{~N}=33)$. Additionally, the concentrations of $\mathrm{PM}_{10}$, which were the summation of $\mathrm{PM}_{2.5}$ and $\mathrm{PM}_{2.5-10}$ concentrations, had an average concentration of $3215 \pm 4858 \mu_{\mathrm{g} \mathrm{m}}^{-3}(\mathrm{~N}=33)$. The average $\mathrm{PM}_{2.5}$ mass concentrations accounted for $75 \pm 18 \%$ from those of $\mathrm{PM}_{10}$, suggesting that $\mathrm{PM}_{2.5}$ was the main component of particulate matter that the workers were exposed to during the burning activity. The study also found that increased amounts of burnt e-waste significantly influenced the concentrations of coarse and fine particles emitted. Moreover, the Pearson's correlation showed a positive relationship between each type of PM mass concentrations and their own total weighted scores of activity patterns. The results indicated that the activity that most increased the exposure concentration of $\mathrm{PM}_{2.5}$ was mixing e-waste on fire. In contrast, the activities that influenced the exposure of $\mathrm{PM}_{2.5-10}$ are mechanical activities, such as compiling and sweeping of e-waste, which are processes that emit and spread larger sizes of particulate matter into the air around the working environment.
\end{abstract}

Keywords: E-waste open burning, E-waste dismantling workers, $\mathrm{PM}_{2.5}, \mathrm{PM}_{2.5-10}$, Inhalation exposure, Burning activity pattern

\section{Introduction}

In accordance with the high consumption rate and the shorter lifespan of products, the waste of electrical and electronic equipment (WEEE or e-waste) has the fastest generation rate in the world. Thailand also faces the problem of e-waste management due to the large quantity of e-waste generated continuously year by year. According to the Thailand State of Pollution Report published by Pollution Control Department of Thailand [1], the estimated amount of household hazardous waste generated in 2015

\footnotetext{
* Correspondence: Tassanee.c@chula.ac.th

${ }^{2}$ Department of Environmental Science, Faculty of Science, Chulalongkorn University, Bangkok 10330, Thailand

${ }^{3}$ Research Program of Municipal Solid Waste and Hazardous Waste

Management, Center of Excellence on Hazardous Substance Management,

Bangkok 10330, Thailand

Full list of author information is available at the end of the article
}

increased from 2014 by $2.57 \%$, and the largest proportion belonged to e-waste, which accounted for $65 \%$ of all municipal hazardous waste.

Several districts in Kalasin and Buriram Provinces are known to be the main areas where streams of e-waste are received for separation and recycling of valuable components by primitive methods [2]. From the previous study, the procedure of e-waste dismantling by primitive methods from informal separators begins with buying e-waste directly from households or junk shops, piling them up in dismantling workplaces that are mostly located in residences and then, starting the dismantling process, first from large products such as washing machines, refrigerators and air conditioners. The procedure of e-waste separation commonly begins by removing the external structure made of steel, 
aluminum or plastic. Next, the internal parts, such as electric motors, printed circuits boards, and wires, are separated. These components are further smashed and separated to regain the valuable materials inside, mainly copper and steel. Open burning is one of the main processes used in dismantling activities to separate the precious metal from the electrical wires and residues, which can extract a large amount of copper within a shorter time than peeling the wires with cutter equipment [3].

These processes of primitive e-waste recycling techniques are commonly and similarly used by the informal e-waste separators all over the world, with the highest volume of informal e-waste recyclers reportedly found in China, Ghana, Nigeria, India, Thailand, the Philippines, and Vietnam [4]. However, e-waste is chemically and physically distinct from other kinds of waste because it is composed of both useful and valuable materials as well as hazardous toxic substances. Therefore, special disposal and recycling methods are required to avoid the adverse impact on the environment and side effects on human health [5]. In addition, the primitive recycling technique widely used in these developing countries is very unsafe because the procedures used during this technique can disperse severe environmental contamination and detrimental health burdens on workers due to lack of control technology and appropriate protection [6].

Open burning is one of those primitive methods used to separate the copper from the wires that still can be found in Thailand. The e-waste open burning in rural areas cannot be completely controllable due to the lacking of the national regulation. Only Memorandum of Understanding between the e-waste dismantling business owner and the local administrative organizations in district and subdistrict scales was designated. Previous studies revealed that many types of toxic air pollutants can be released from the combustion of e-waste, including dioxins, furans, hydrogen chloride, polyhalogenated aromatic hydrocarbons (PHAHs), polycyclic aromatic hydrocarbons (PAHs) and a significant amount of particulate matter [7]. Zheng et al. [8] collected the daily samples of $\mathrm{PM}_{2.5}$ in the ambient air of a community with an e-waste dismantling site in Guiyu, China. The study found that the geometric mean of $\mathrm{PM}_{2.5}$ concentrations in Guiyu was significantly higher than that in the reference area without e-waste recycling work; moreover, this level of concentration also exceeded the current World Health Organization (WHO) 24-h and annual $\mathrm{PM}_{2.5}$ ambient air quality guidelines and the Chinese 2012 National Ambient Air Quality Standards (NAAQS) Level I. Furthermore, Gangwar et al. [9] found that the highest mean concentration of $\mathrm{PM}_{10}$ belonged to the residential located together with e-waste burning area, and those found to be higher than other sampling sites without e-waste burning activity. The detected $\mathrm{PM}_{10}$ mean concentration at the site also exceeded the NAAQS value notified by Central Pollution Control Board, Ministry of Environment and Forests of India. The study also suspected that the higher concentrations of $\mathrm{PM}_{10}$ at the ewaste burning site might occur from e-waste crude recycling operations such as dismantling, combustion, incineration, and open burning procedure. In addition, the preliminary research in Buriram Province found that the concentration of $\mathrm{PM}_{10}$ obtained from the day that workers performed open burning activities was $0.461 \mathrm{mg} \mathrm{m}^{-3}$, higher than the average $\mathrm{PM}_{10}$ from other separation activities $\left(0.0646 \mathrm{mg} \mathrm{m}^{-3}\right)$ by about seven-fold [10]. This result revealed that workers who perform burning activities might have higher exposure to particulate matter as well as other toxic substances adsorbed on the surface of particles. However, there is no study about the concentration of PM emitted into the environment from the open burning of e-waste directly. Therefore, this research aims to study the emission of coarse and fine particles from the open burning of e-waste in Buriram Province, Thailand. The measured results will be used to further assess the health risk from each route of contact for the dismantling workers at this site. The research outcomes can be used to develop warning guidelines for workers and for further surveillance and management planning to protect both people and environment.

\section{Materials and methods}

\section{Studied area and population}

The sampling site in this study was located in Daeng-Yai subdistrict, Buriram Province, which is well-known to be one of the major spots in Thailand where a large stream of e-waste is continuously transported to informal ewaste dismantling sectors in the area for separating activities. After the disassembling of the external parts of electric and electronic equipment, the small internal parts of the waste that could not be separated, such as electrical wire, small motors, and ballasts, are stored until the quantity of valuable metals is sufficient to burn. Then, the separators load the collected waste into containers and transport them by truck from the dismantling sites in the village to the central landfill for burning. This central landfill $\left(15^{\circ} 34.819^{\prime} \mathrm{N} 102^{\circ} 52.787^{\prime} \mathrm{E}\right)$-the sampling site of this study-was the remote unused land permitted by the local government and authorities as the place where villagers, including people who work there as e-waste separators, could dispose and open burn their waste. The distance from the middle of the village to the central landfill is about $1.3 \mathrm{~km}$ (Fig. 1).

The particulate matter samples in this study were collected from the breathing zone of workers who perform open burning of e-waste at the central landfill. All of the population in this study was suggested by local authorities and voluntarily agreed to wear the sampling equipment during their burning activities. The involvement of 


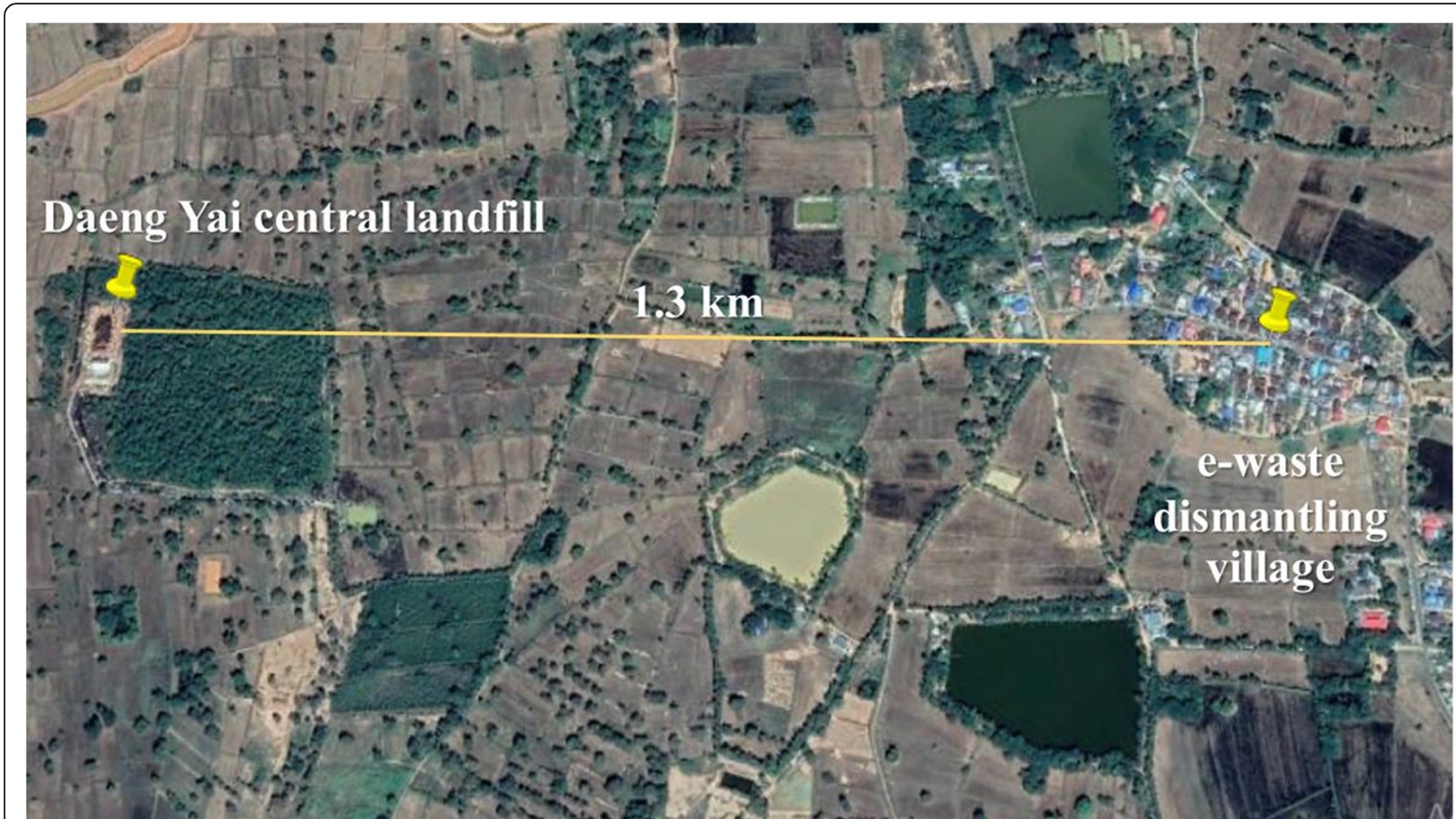

Fig. 1 The waste transportation route from e-waste dismantling village to Daeng-Yai central landfill (Source: Google Earth Pro Program (Date of access: March 4, 2019))

participants in this study was approved by the Ethics Review Committee for Research Involving Human Research Subjects, Health Sciences Group, Chulalongkorn University, responsible for ethics on human and/or animal experimentation with the certificate of approval number (COA No. 230/2016).

\section{Preparation methods for inhalation exposure sampling}

In this study, the samples of $\mathrm{PM}_{2.5}$ and $\mathrm{PM}_{2.5-10}$ were collected by using polytetrafluoroethylene (PTFE) filters with $37 \mathrm{~mm}$ diameter and $2 \mu \mathrm{m}$ pore size and PTFE filters with $25 \mathrm{~mm}$ diameter and $0.2 \mu \mathrm{m}$ pore size, respectively, those of which recommended by the manufacturer to use with a Personal Modular Impactor (PMI) sampler models (SKC, Cat. No. 225-351) [11]. All of the filters were prepared by keeping in an electrical auto-dry desiccator (AS ONE, model OH-3S, Cat. No. 1-5486-21) for at least $24 \mathrm{~h}$ to reduce the moisture content that was entrapped into the filters. This auto-dry desiccator had dehumidification system using solid high polymer electrolyte membrane and $\mathrm{H}_{2} \mathrm{O}$ electrolytic discharge that could control the internal humidity at $25 \%$ relative humidity. Then, the mass of the prepared filters was quantified by gravimetric analysis and stored in plastic cases waiting to be placed in the cassettes of the PMI samplers in preparation for the sampling period.

The personal air samplers (SKC Airchek Sampler, model 224-PCXR8) were calibrated by the primary gas flow calibrator (Defender 530, Drycal TECHNOLOGY) to a sampling flow rate of $3 \mathrm{~L} \mathrm{~min}^{-1}$. Then, the whole set of equipment, including the personal air samplers and the PMI samplers that already contained both sizes of prepared filters, were connected by tubes and ready for sampling.

\section{Sampling method}

The whole set of sampling equipment was installed on each worker who was going to burn e-waste. The PMI was attached to the worker's collar in order to be representative of their breathing zone, which is the hemisphere in front of the shoulders within a radius of approximately 15 to $23 \mathrm{~cm}$. The personal air sampler, which was attached to the worker's belt, was turned on when the worker started burning activities and was stopped when the worker finished e-waste burning work. The total sampling time, amount of e-waste for burning, composition of e-waste and the activity of each worker were observed and recorded for each sampling period.

After sampling finished, the flow rates of the personal air samplers were measured to calculate the volume of airflow through the pump. The sampled filters were kept in opaque plastic cases with all joints sealed for transport to the laboratory where they were stored in a desiccator for at least $48 \mathrm{~h}$ before weighing by gravimetric analysis.

Blank samples in this study were field blank, which is defined as a clean sample of a matrix taken from the 
laboratory to the sampling site and transported back to the laboratory without having been exposed to sampling procedures [12]. Both sizes of blank filters were transported to the e-waste burning site every sampling period and sealed for the return trip to the laboratory where they were stored using the same storage method as the samples for gravimetric analysis.

\section{Additional data collection during inhalation sampling}

During every sampling period, data about the factors that may have an impact on the results-including meteorological data, types of burnt e-waste, quantity of burnt e-waste, total sampling time, individual patterns of burning activities and the use of personal protective equipment-were all recorded. Meteorological data including temperature, pressure, and humidity were measured by a hygrometer, and wind speed and wind direction were obtained from satellite data in a real-time mobile application (Weather, Apple, 2016-2018). The quantity of burnt e-waste was approximately weighed by the workers before transport to the landfill. Additional data were recorded by real-time observation during burning activities. A description of the samples collected is summarized in Table 1. The data provided in the table include the characteristics of collected samples and the number of each type of sample.

\section{Gravimetric analysis}

Gravimetric analysis is a common technique used to determine the mass or concentration of a substance by measuring a change in mass. In this study, the filters that were used for sampling along with the blank filters were weighed with a 7 decimal place ultra-microbalance (Mettler Toledo: METLER UMX 2), both before and after collecting the samples to obtain the net difference in mass. The change in weight before and after sampling was used for PM mass calculation, and the concentrations of PM $\left(\mu \mathrm{g} \mathrm{m}^{-3}\right)$ were obtained from the masses of the PM divided by the change in the volume of air that passed through the personal pumps during each sampling period.

\section{Quality control}

In order to control the quality of the gravimetric analysis procedures, the Mettler Toledo: METLER UMX 2, with a sensitivity of $0.001 \mathrm{mg}$, was selected for measuring mass. This microbalance must be used in a conditioned room that was the closed and cleaned room, which the temperature was continuously controlled at $24 \pm 1{ }^{\circ} \mathrm{C}$. The standard pendulum, 200 and $100 \mathrm{mg}$, were weighed every day before the start and after the finish of filter weighing in order to calibrate the analytical balance daily, and thus, control the quality of the analysis. In addition to rechecking the reliability of the gravimetric analysis and minimizing the error from any interference during the weighing process that could affect the obtained values of mass, every filter was weighed three times each, both before and after sampling. These three values of filter mass were averaged to determine the final gravimetric mass of each filter. According to the gravimetric analysis in this study, the standard deviations obtained from the three times weighing masses of entire 25 and $37 \mathrm{~mm}$ filters both before and after sampling were all less than $0.0004 \mathrm{mg}$.

\section{Calculation}

In order to transform the recorded data of burning activity patterns into a numerical quantity for statistical analysis, the information was decoded into the form of scores calculated by Eqs. (1)-(2). Regarding to lack of emission factors of particulate matter from each activity in burning process of e-waste, the weight of scores were then valued according to the probability of the emission source of each type of particle, and arranged in order by the significance of each activity in terms of the impact of each type of PM on the mass concentration. The highest

Table 1 Description of the samples in this study

\begin{tabular}{|c|c|c|}
\hline $\begin{array}{l}\text { Types of } \\
\text { samples }\end{array}$ & Characteristic of collected samples & Number of samples \\
\hline $\begin{array}{l}\text { Personal } \\
\text { inhalation } \\
\text { exposure }\end{array}$ & $\mathrm{PM}_{2.5-10}$ and $\mathrm{PM}_{2.5}$ & $N=33$ for each types of PM \\
\hline $\begin{array}{l}\text { Additional } \\
\text { data }\end{array}$ & $\begin{array}{l}\text { Recorded data during every sampling times, } \\
\text { including } \\
\text { 1. Meteorological data, consisted of } \\
\text { temperature, pressure, humidity, wind speed, } \\
\text { and wind direction } \\
\text { 2. Types of burnt e-waste } \\
\text { 3. Quantity of burnt e-waste } \\
\text { 4. Total sampling time } \\
\text { 5. Pattern of burning activity } \\
\text { 6. The use of personal protective equipment } \\
\text { (PPE) }\end{array}$ & $\begin{array}{l}\text { For meteorological data, types and quantity of burnt e-waste, and total } \\
\text { sampling time, the amounts of data were in accordance with the sampling } \\
\text { times. For pattern of burning activity and the use of PPE, the number of data were } 33 \text {. }\end{array}$ \\
\hline
\end{tabular}


score for each type of PM went to the activity that was suspected to be the major source of the particle emissions.

$$
\begin{aligned}
\text { Activity score PMi }= & \text { WSPMi } \\
& \times(\% \text { burning activity } / 100)
\end{aligned}
$$

Total activity score PMi $=\Sigma$ activity score PMi

where; activity score PMi = The score of burning activity for each size of PM WSPMi = Weight of scores for source strength of each size of PM (in Table 2).

The weighing score approach was implemented to verify the relationship between concentrations of emitted particulate matter involved with time and activities that were considered as the possible sources of each type of particulate matter. For fine particle samples, the main source of $\mathrm{PM}_{2.5}$ comes from an incomplete combustion process [13]; therefore, the activity that had the most impact on $\mathrm{PM}_{2.5}$ mass concentrations was suspected to be the fire mixing process, which the workers spend most of their time closest to the smoke fumes. Thus, the weighting score for fire mixing process was designated to be 100 compared with other activities. The second highest impact activity was anticipated to be the sweeping process, followed by the pounding and compiling of the waste, respectively. Hence, the weighting scores were ranged decreasingly as the reduction of significance of the sources and the scores needed to be distinct enough to see the difference.

In contrast, to examine the types of activities that had relationships with coarse particle samples, the same conversion of burning activity to numerical quantities method was implemented. The primary source of $\mathrm{PM}_{2.5-10}$ comes from the more mechanical processes rather than the sources of $\mathrm{PM}_{2.5}$ [13], so the activity that was suspected to have the most impact on $\mathrm{PM}_{2.5-10}$ was the compiling process, followed by pounding, sweeping and fire mixing to the pile of waste, respectively. The weight of scores for each process for $\mathrm{PM}_{2.5}$ and $\mathrm{PM}_{2.5-10}$ samples is shown in Table 2 and the percentages of burning processes for each activity pattern, which were concluded from observation during sampling, are summarized in Table 3 shown in the results and discussion section.

\section{Results and discussion}

Observed data during site sampling

Meteorological data

All of the samples in this study were collected from February to August 2017, which corresponds to the duration from summer to rainy season in Thailand. The temperature ranged from 25 to $34{ }^{\circ} \mathrm{C}$ with a mean value at $28.7^{\circ} \mathrm{C}$, while the relative humidity ranged from 56 to $87 \%$ with an average percent of $72 \%$. The pressure ranged from 100.58 to $101.59 \mathrm{kPa}$ with an average value of $101.05 \mathrm{kPa}$. The wind speed ranged from 0.48 to 4.92 $\mathrm{m} \mathrm{s}^{-1}$, with an average velocity at $2.82 \mathrm{~m} \mathrm{~s}^{-1}$.

\section{Types and quantity of burnt e-waste}

The streams of e-waste that would be burnt each time varied in terms of types and quantity depending on the waste that the workers received from the middlemen. Types of burnt e-waste were mostly electrical wires, small motors and some other residue parts that contained valuable metals that could not be separated by mechanical processes, such as small pieces of ballasts and circuits. Some of the discarded residues, for example, polyurethane foam in refrigerators, tires and papers from the bases of electric fans, were burnt together with e-waste and served as fuel. The same team of workers who performed the burning work together also shared an equal of types and amounts of e-waste for burning. The quantity of e-waste to be burned in this study was approximately weighed by the workers at their dismantling sites before transport to the landfill. The amount ranged from 100 to $300 \mathrm{~kg}$, and the average amount of waste was $201.52 \mathrm{~kg}$. The information about the types and quantity of burnt e-waste for each group of workers is summarized in Table 4.

\section{Pattern of burning activity}

Regarding the observation record, procedures for e-waste burning were separated into five important activities after the waste was delivered to the landfill, including piling of waste, fire mixing of the pile of waste, sweeping the small residue metals after burning processes are complete, compiling the metal after finishing and pounding the finished burnt waste to remove the non-valuable leftover. The personal air samplers were turned on at the beginning of the fire mixing process when the workers lit the fire in the piles of waste. The sampling periods ended when the

Table 2 The weight of scores of related burning process considerable as source of $\mathrm{PM}_{2.5}$ and $\mathrm{PM}_{2.5-10}$

\begin{tabular}{lll}
\hline Activities & Weight of scores for $\mathrm{PM}_{2.5}$ source strength $\left(\mathrm{WS}_{\mathrm{PM} 2.5}\right)$ & Weight of scores for $\mathrm{PM}_{2.5-10}$ source strength $\left(\mathrm{WS}_{\mathrm{PM} 2.5-10}\right)$ \\
\hline Fire mixing $(\mathrm{F})$ & 100 & 1 \\
Sweeping $(\mathrm{S})$ & 50 & 2 \\
Pounding $(\mathrm{P})$ & 2 & 5 \\
Compiling $(C)$ & 1 & 100 \\
\hline
\end{tabular}


Table 3 Percentages of each burning activities of the workers

\begin{tabular}{|c|c|c|c|c|c|}
\hline \multirow{2}{*}{$\begin{array}{l}\text { Code } \\
\text { of } \\
\text { activity } \\
\text { pattern }\end{array}$} & \multirow{2}{*}{$\begin{array}{l}\text { Worker who proceeded } \\
\text { the pattern }\end{array}$} & \multicolumn{4}{|c|}{ Percentages of each burning activities (\%) } \\
\hline & & Fire mixing & Sweeping & Pounding & Compiling \\
\hline AP1 & W10 & 5 & 95 & - & - \\
\hline AP2 & W3 & 10 & 90 & - & - \\
\hline AP3 & W8 & 55 & 45 & - & - \\
\hline AP4 & W7, W18, W23 & 60 & 40 & & \\
\hline AP5 & W4, W6, W25, W31, W32 & 70 & 30 & - & - \\
\hline AP6 & $\begin{array}{l}\text { W11, W14, W15, W20, } \\
\text { W22, W26, W27, W28, } \\
\text { W29, W30, W33 }\end{array}$ & 80 & 20 & - & - \\
\hline AP7 & W9, W12 & 90 & 10 & - & - \\
\hline AP8 & W1, W2 & 60 & - & 40 & - \\
\hline AP9 & W19 & 35 & 50 & - & 15 \\
\hline AP10 & W21 & 50 & 30 & - & 20 \\
\hline AP11 & W24 & 70 & 10 & - & 20 \\
\hline AP12 & W16, W17 & 70 & 20 & - & 10 \\
\hline AP13 & W5, W13 & 80 & 10 & - & 10 \\
\hline
\end{tabular}

Table 4 Types and quantity of burnt e-waste for each group of workers

\begin{tabular}{|c|c|c|c|}
\hline No. of sampling time & Code of workers & Quantity of burnt e-waste (kg) & Types of burnt e-waste \\
\hline 1 & W1-W2 & 100 & $\begin{array}{l}\text { - Electrical wires } \\
\text { - Motor from motorcycles and drills }\end{array}$ \\
\hline 2 & W3-W5 & 150 & $\begin{array}{l}\text { - Electrical wires } \\
\text { - Telephone wires }\end{array}$ \\
\hline 3 & W6-W7 & 100 & $\begin{array}{l}\text { - Electrical wires } \\
\text { - Motor from televisions and hair dryers } \\
\text { - Accessories from CD players }\end{array}$ \\
\hline 4 & W8-W9 & 100 & - Electrical wires \\
\hline 5 & W10-W13 & 200 & $\begin{array}{l}\text { - Electrical wires } \\
\text { - Motor } \\
\text { - Electric fan guard }\end{array}$ \\
\hline 6 & W14-W17 & 200 & $\begin{array}{l}\text { - Electrical wires } \\
\text { - Motors from drills } \\
\text { - Printer accessories }\end{array}$ \\
\hline 7 & W18-W21 & 250 & $\begin{array}{l}\text { - Electrical wires } \\
\text { - Refrigerator doors }\end{array}$ \\
\hline 8 & W22-W25 & 150 & $\begin{array}{l}\text { - Electrical wires } \\
\text { - Motors from televisions }\end{array}$ \\
\hline 9 & W26-W29 & 300 & $\begin{array}{l}\text {-Electrical wires } \\
\text { - Motors from hair dryers, } \\
\text { blenders, and aquarium power filters } \\
\text { - Electrical circuits from } \\
\text { televisions and computers }\end{array}$ \\
\hline 10 & W30-W33 & 300 & $\begin{array}{l}\text {-Electrical wires } \\
\text { - Motors } \\
\text { - Refrigerator doors }\end{array}$ \\
\hline
\end{tabular}


workers finished their compiling or pounding of waste. Most of the workers took the finished burnt waste to pound at their dismantling sites. Therefore, this research mainly focused on only four burning activities during sampling time, i.e., fire mixing, sweeping, pounding and compiling as shown in Fig. 2.

The pattern of burning activities among the workers in this study could be approximately divided into 13 distinct patterns classified by the percentage of each burning process as shown in Table 3. The proportion of each activity was estimated from the time that each activity took relative to the total sampling time, which was demonstrated in Fig. 3, and divided to calculate percentages. The proportion and types of activities varied from the responsibility that each worker carried from work sharing in their teams, so some workers did only some activities while others performed a complete cycle of the burning process.

The proportions of burning processes accounted in each activity pattern were also supported by face-to-face interviews with each worker about their work plan and work sharing in their groups on the sampling day to take into consideration the duty of each worker in order to estimate the main activity each of them took responsibility for. The proportions of burning processes accounted for in each activity pattern is summarized in Fig. 4, which illustrates the different percentage of each activity within the 13 activity patterns.

\section{Particulate matter concentrations}

The concentrations of $\mathrm{PM}_{2.5-10}$ ranged from 68 to $2285 \mu \mathrm{g} \mathrm{m}^{-3}$ with an average concentration of $441 \mu \mathrm{g} \mathrm{m}^{-3}$ $(N=33)$. For $\mathrm{PM}_{2.5}$, the concentrations ranged from 144 to $17,430 \mu \mathrm{g} \mathrm{m}^{-3}$ and the mean concentration was $2774 \mu \mathrm{g} \mathrm{m}^{-3}(\mathrm{~N}=33)$. The concentrations of $\mathrm{PM}_{10}$, which are the summation of $\mathrm{PM}_{2.5}$ and $\mathrm{PM}_{2.5-10}$ concentrations, ranged from 232.to $18,361 \mu \mathrm{g} \mathrm{m}^{-3}$ with an average concentration of $3215 \mu \mathrm{g} \mathrm{m}^{-3}(\mathrm{~N}=33)$. Compared with other studies, the average concentration of $\mathrm{PM}_{2.5}$ collected from direct e-waste burning process in this study was obviously higher than the average ambient $\mathrm{PM}_{2.5}$ concentration that was measured from the air in an informal electronic waste recycling site in China $\left(49.9 \mu \mathrm{g} \mathrm{m}^{-3}\right)$ by about 56 times [8]. The mean concentration was also higher than the average $\mathrm{PM}_{2.5}$ concentration collected from ambient air in the big e-waste industrial park in Fengjiang, a small town of the Luqiao district of Taizhou, Zhejiang Province in China $\left(49.6 \mu \mathrm{g} \mathrm{m}^{-3}\right.$ in summer and $153.9 \mu \mathrm{g} \mathrm{m}^{-3}$ in winter) by 18.0- to 55.9-fold, respectively [14]. The average concentration of $\mathrm{PM}_{2.5}$ in this study was also significantly larger than the average concentration of $\mathrm{PM}_{2.5}$ sampled from the e-waste mechanical workshop in China $\left(271.7 \mu \mathrm{g} \mathrm{m}^{-3}\right)$ by about 10 times [15]. Furthermore, the mean concentration of $\mathrm{PM}_{2.5}$ in this study was much higher compared with those collected within Guiyu and Qingyuan, the two important e-waste recycling regions of South China where were operated after the prohibition of open burning process from the new stringent controlling policy in 2010 (30.4 and $27.8 \mu \mathrm{g} \mathrm{m}^{-3}$ ) by about 91 and 100 times, respectively [16]. The result revealed that the open burning process of e-waste emitted a significant amount of particulate matter, which was distinctly higher than the concentrations detected in the ambient atmosphere of the e-waste recycling site and the concentration from other processes of e-waste dismantling activities. Thus, the workers who performed the burning work have greater exposure to coarse and fine particulate matter that also contains other types of pollutants adsorbed on the surface of the particles, likely leading to more severe health consequences later on.

The average $\mathrm{PM}_{2.5-10}$ concentration in this study was compared with Ogundele et al. [17], who identified the potential sources responsible for the particulate matter emission from a secondary iron and steel smelting factory environment. $\mathrm{PM}_{2.5-10}$ particles were collected using the low-volume air samplers twice a week for a year. The average mass concentration of $\mathrm{PM}_{2.5-10}$ in this study was apparently higher than those that were detected in the production, outside (upwind) and outside (downwind) sites in an iron and steel scrap smelting factory (the average mass concentrations of $\mathrm{PM}_{2.5-10}$ were

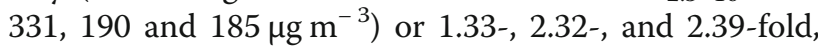
respectively. This comparison supports the conclusion that open burning of e-waste can generate significantly high concentrations of particulate matter, not only of $\mathrm{PM}_{2.5}$, but also of $\mathrm{PM}_{2.5-10}$.

According to Pearson's correlation statistical analysis, the mass concentrations of $\mathrm{PM}_{2.5}$ and $\mathrm{PM}_{2.5-10}$ had no

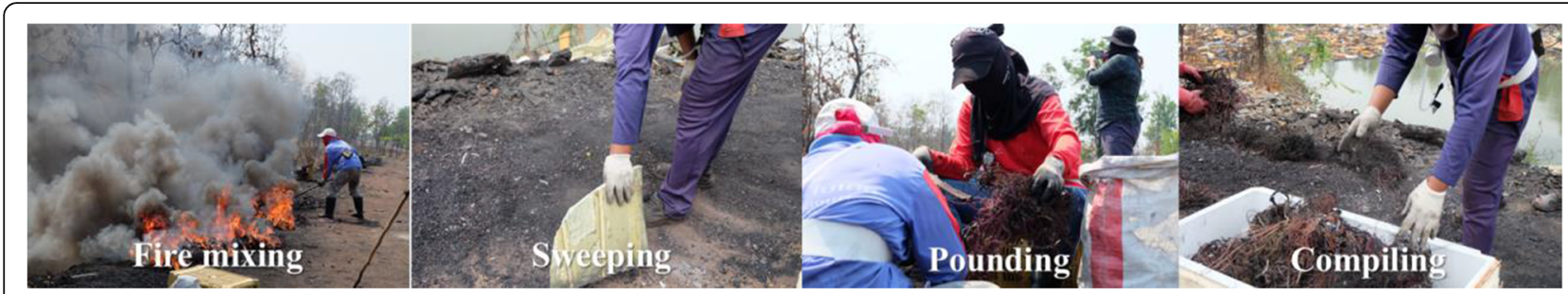

Fig. 2 The four significant burning activities 


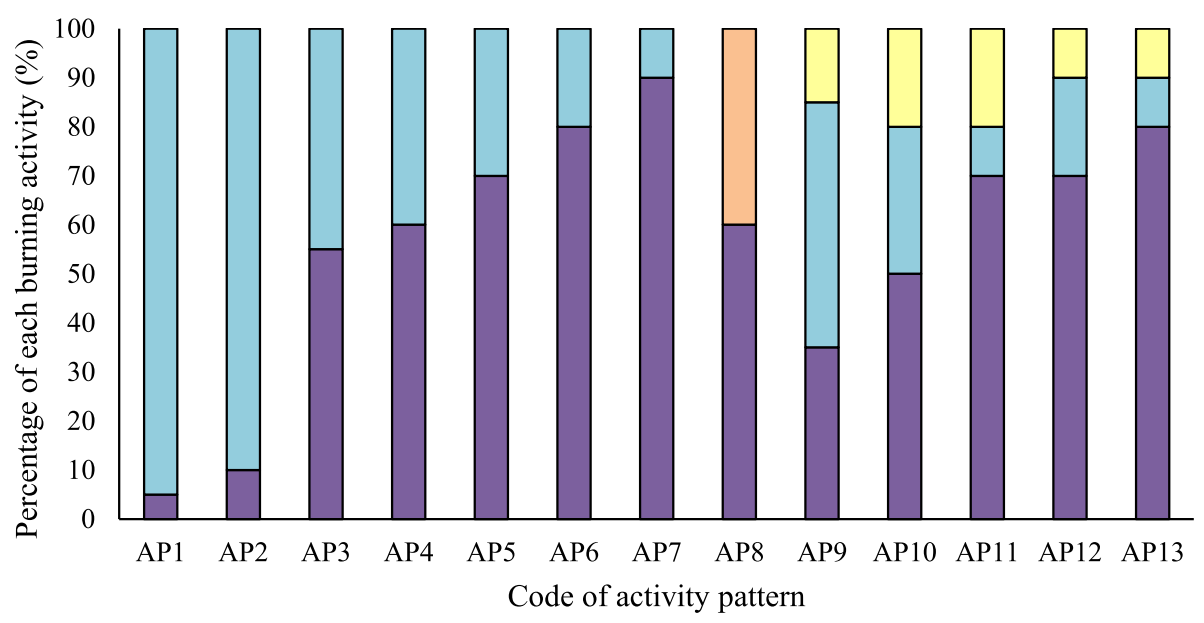

$\square$ Fire mixing $\quad \square$ Sweeping $\quad \square$ Pounding $\square$ Compiling

Fig. 4 The proportions of burning processes accounted in each activity pattern

significant relationship with each other $(p=0.172)$, and for which the concentration of each type of PM might be involved with other specific factors to be discussed in the next section. As same as the relationship between $\mathrm{PM}_{2.5-10}$, and $\mathrm{PM}_{10}$ concentrations, Pearson's correlation statistical analysis showed a non-significant correlation for both types of particulate matter $(p=0.054)$. However, there was a strong positive relationship between $\mathrm{PM}_{2.5}$ and $\mathrm{PM}_{10}$ mass concentrations $(r=0.995$, $p=0.000)$, which indicates that the higher the concentrations of $\mathrm{PM}_{2.5}$, the higher the total concentrations of $\mathrm{PM}_{10}$. Figure 5 shows the percentage of $\mathrm{PM}_{2.5}$ in proportion to $\mathrm{PM}_{10}$ mass concentrations. The average $\mathrm{PM}_{2.5}$ mass concentrations accounted for $75 \pm 18 \%$ of the $\mathrm{PM}_{10}$ mass concentrations, suggesting that $\mathrm{PM}_{2.5}$ was the main component of $\mathrm{PM}_{10}$ in this study. This finding suggests that $\mathrm{PM}_{2.5}$ was the primary type of particulate matter emitted directly from the open burning activities, which were part of the incomplete combustion process [18].

Some previous studies revealed that many types of toxic air pollutants both in gas phase and particulate phase can be released through atmospheric environment from the open combustion of e-waste, including various species of heavy metal, dioxins, furans, hydrogen chloride, PHAHs, and PAHs [7]. Due to the high concentrations of $\mathrm{PM}_{2.5}$ and $\mathrm{PM}_{2.5-10}$ found in this study, the further quantification analysis of toxic chemicals in particulate phase was suggested to be performed, and the measured results can also be used in the further step to assess the health risk of the dismantling workers in

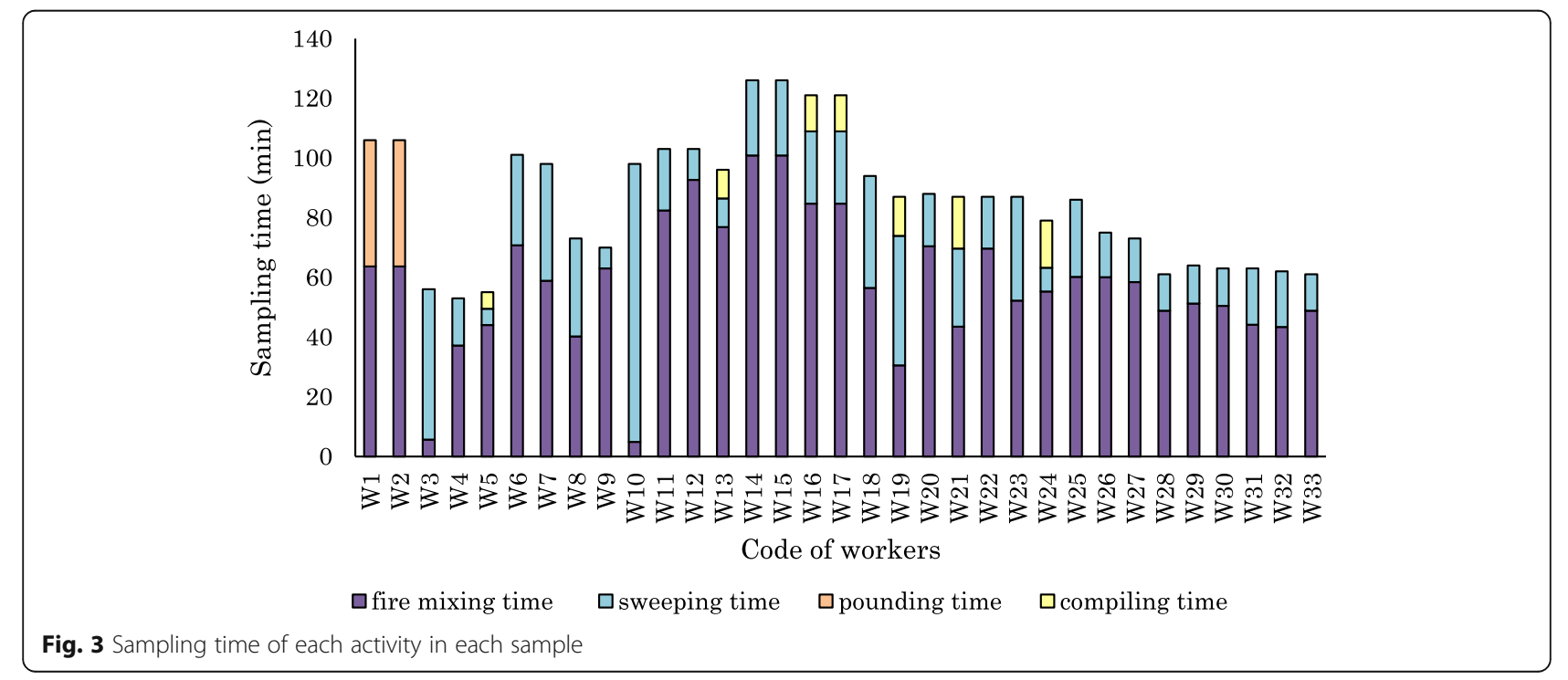




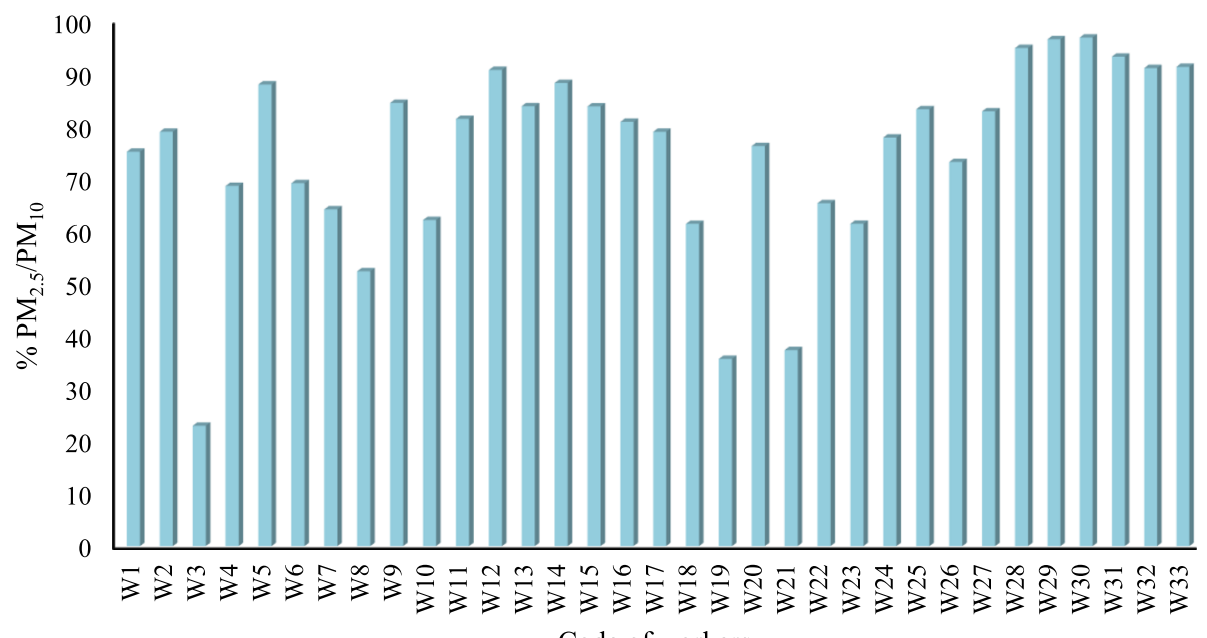

Fig. 5 Percent contribution of $\mathrm{PM}_{2.5}$ in $\mathrm{PM}_{10}$ from each sample

this site from inhalation contact. Then, the outcomes of this research can be served as the warning guideline for workers and for further surveillance and management planning to protect both people and environmental health.

\section{Factors affecting particulate matter concentrations from e-waste burning activity}

The personal exposure concentrations of $\mathrm{PM}_{2.5}$ and $\mathrm{PM}_{2.5-10}$ in this study had no statistically significant relationship with meteorological conditions, including temperature, humidity, pressure and wind speed, during the sampling period. The reason probably stems from the very specific activity of the open burning process that releases very high amounts of particulate matter within a short period of time. Moreover, the weather for outdoor open burning needs to be dry with no rain, so the humidity was low. Consequently, the meteorological factors did not clearly show impact or involvement in the obtained concentrations of both types of particulate matter. Even though the relationship between these factors did not statically show, the impact of wind speed and wind direction possibly could disperse the plume of contaminated particulate matter from open burning of e-waste to the downstream residential area, so the prevention strategy is also required. In addition, there were other related factors that had relationships with the concentrations of particulate matter from open burning of e-waste, which are discussed in the following section.

\section{The quantity of burnt e-waste}

The correlation between the quantity of burnt e-waste and the concentrations of $\mathrm{PM}_{2.5-10}$ analyzed by Pearson's correlation suggest a weakly positive relationship $(r=$ 0.393, $p=0.024)$. Furthermore, the Pearson's correlation between the quantity of burnt e-waste and the concentrations of $\mathrm{PM}_{2.5}$ could demonstrate a significant positive relationship with the quantity of burnt e-waste $(r=0.627$, $p=0.000$ ). Consequently, these results show that increasing amounts of burnt e-waste influence the higher concentration of particulate matter emitted through the ambient air in particular fine particles.

\section{Pattern of burning activities}

The Pearson's correlation between the mass concentrations of $\mathrm{PM}_{2.5}, \mathrm{PM}_{2.5-10}$ and the total scores of burning activity patterns for each type of particulate matter samples was examined to investigate the relationship between factors. The results obtained showed a positive relationship between $\mathrm{PM}_{2.5}$ concentrations and the total scores of activity patterns that were highest for the fire mixing process, followed by the sweeping process, pounding and compiling of waste, respectively $(r=0.305$, $p=0.084) . \mathrm{PM}_{2.5-10}$ mass concentrations also had a positive correlation with their own total scores of activity patterns that were highest for the compiling process, followed by pounding, sweeping and fire mixing of the pile of waste ( $r=0.397, p=0.022)$.

Figure 6 presents the contribution of the average concentrations of each type of PM generated from each activity pattern. The lower and upper parts of the bars represent the concentrations of $\mathrm{PM}_{2.5}$ and $\mathrm{PM}_{2.5-10}$, respectively, while $\mathrm{PM}_{10}$, which is the summation of both types of particulate matter, is presented by each entire bar. These results indicate that the activity exhibiting the most effect on increasing the concentrations of $\mathrm{PM}_{2.5}$ is the fire mixing process during which time the workers have to be close to or directly covered by the smoke fumes for the period of work time. Therefore, exposure to fine particles generated from the incomplete combustion 


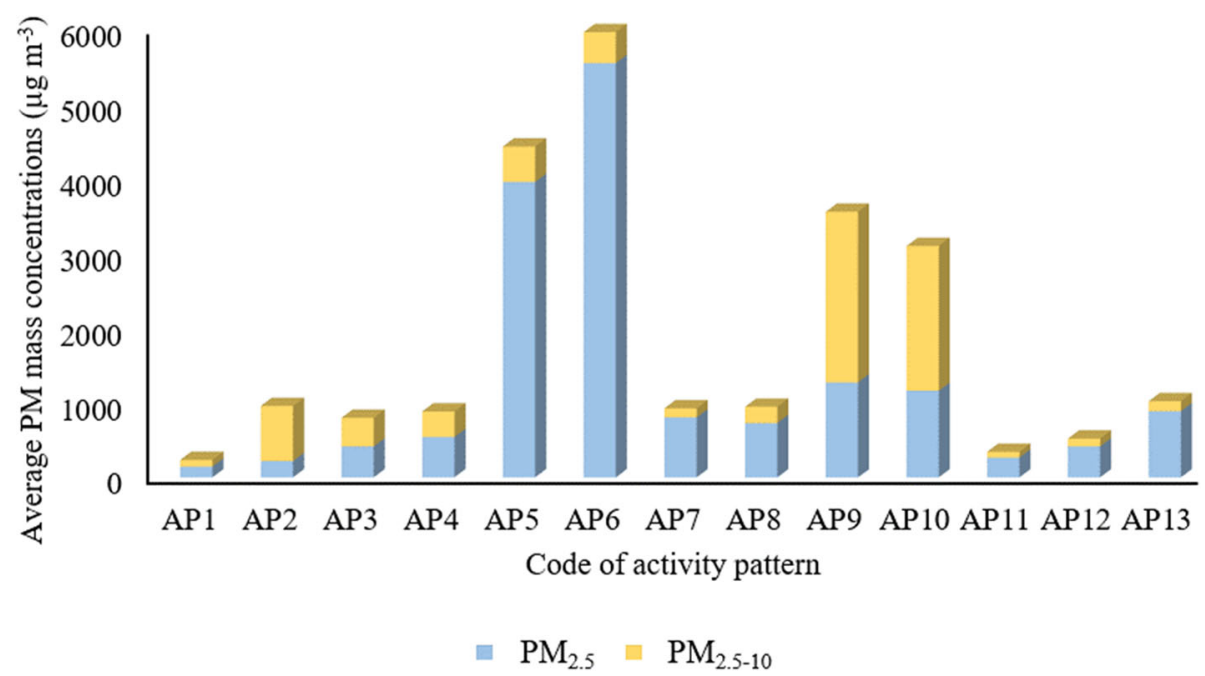

Fig. 6 Average concentrations of $\mathrm{PM}_{2.5}$, and $\mathrm{PM}_{2.5-10}$ generated from each activity pattern

process would be higher than for other activities. In contrast, the activities that influenced the mass concentrations of $\mathrm{PM}_{2.5-10}$ were the more mechanical activities, such as compiling and sweeping of waste, which are processes that emit and spread coarser particulate matter into the air around the working environment.

The $\mathrm{PM}_{2.5} / \mathrm{PM}_{10}$ ratio generated from each activity pattern was quantified as shown in Fig. 7, the pattern that obtained the highest $\mathrm{PM}_{2.5} / \mathrm{PM}_{10}$ ratio was $\mathrm{AP7}$ (0.88), followed by AP6 (0.85) and AP5 (0.81). These three activity patterns consisted of the highest percent of fire mixing activity among all of 13 activity patterns, which fire mixing process was considered to be the major source of $\mathrm{PM}_{2.5}$ that workers were possibly exposed via inhalation in this study. The higher $\mathrm{PM}_{2.5} /$ $\mathrm{PM}_{10}$ ratio indicated the higher emitted $\mathrm{PM}_{2.5}$ concentrations contributed to the total concentrations of $\mathrm{PM}_{10}$. Air Quality Expert Group of UK [19] also supported that the emissions from combustion processes are generally associated with high values of $\mathrm{PM}_{2.5} / \mathrm{PM}_{10}$ ratio, for example, the $\mathrm{PM}_{2.5} / \mathrm{PM}_{10}$ ratio for vehicle exhausts was 0.95. Whilst PM emissions from more mechanical processes or non-combustion sources, such as mining, quarrying, and agriculture, are associated with less $\mathrm{PM}_{2.5} / \mathrm{PM}_{10}$ ratios revealing that a higher proportion of the emitted PM mass is in the coarse mode.

\section{Conclusions}

The mass concentrations of both fine and coarse particulate matter could be generated from the e-waste open burning. The average $\mathrm{PM}_{2.5}$ mass concentrations accounted greater than half of the total $\mathrm{PM}_{10}$ mass concentrations, suggesting that $\mathrm{PM}_{2.5}$ was the main component of $\mathrm{PM}_{10}$ and was also the primary type of particulate matter emitted directly from the open burning activities. There are significant influencing factors that can affect the workers exposed to the particulate

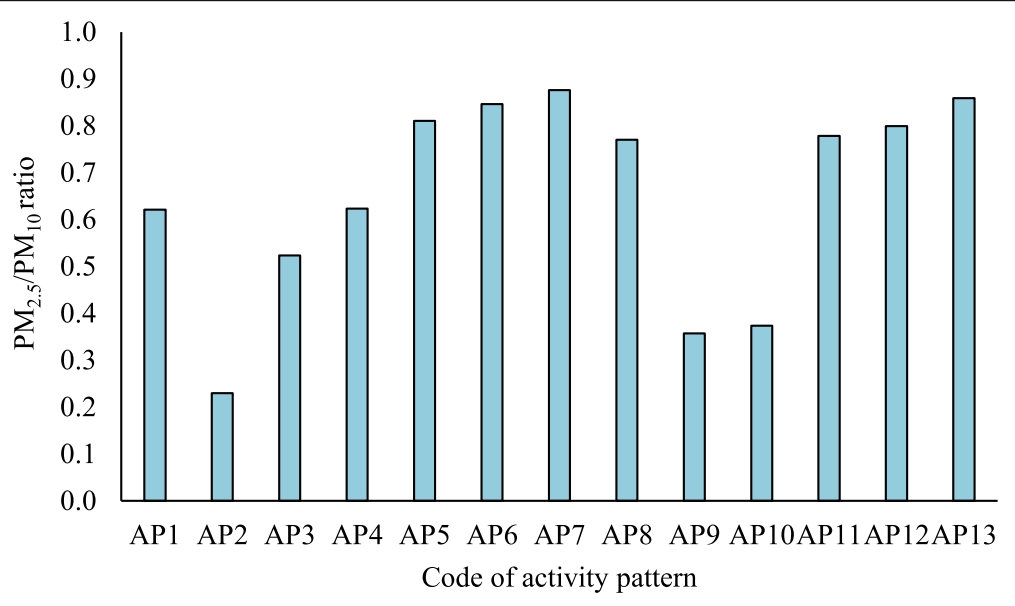

Fig. $7 \mathrm{PM}_{2.5} / \mathrm{PM}_{10}$ ratio generated from each activity pattern 
matter from e-waste burning activity through inhalation, including the quantity of burnt e-waste and the pattern of burning activities. Firstly, the increased amount of burnt ewaste influenced the concentration of coarse and fine particles emitted. Secondly, the activity that had more effect to increase the concentration of $\mathrm{PM}_{2.5}$ was fire mixing. In contrast, the activities that influenced the mass concentration of $\mathrm{PM}_{2.5-10}$ were mechanical activities, such as compiling and sweeping of waste. In addition, due to the significant high concentrations of particulate matter released from open burning of e-waste in this study, the workers would be recommended to avoid being covered or close to the fume of e-waste burning smoke directly in order to reduce the exposure time and health consequences. The burning workers would be also necessarily advised to wear appropriate personal protective equipment for inhalation exposure protection. The high efficient masks that have ability to filtrate $\mathrm{PM}_{2.5}$, i.e., KN95 and N95 masks should be required to be the guard against the dense of both two types of particulate matter. Besides, the local government should present the alternative way for workers to reduce e-waste open burning activity, for example providing electrical wire peeling machine to separate the copper from the wire by mechanical process instead of using burning method.

Nonetheless, quantification the direct emission of coarse and fine particulate matter from each type of burnt e-waste should be investigated to be able to explicit the amount of discharge from the burning activity. Regarding there might have various toxic substances existing in the PM released from the e-waste burning, the further analysis of chemical composition in particulate matters should be examined. So that the negative health consequences of the workers possibly exposed to can be estimated through the health risk assessment, which will be useful for designating a warning guideline for workers as well as a specification of the most proficient management plan to protect both local people health and the environmental.

\section{Acknowledgments}

The authors wish to thank the e-waste workers in Daeng-Yai subdistrict, Banmaichaiyapot District, Buriram Province. This study could not be accomplished without cooperation from them. The sincere gratitude is also extended to all local organizations who offered cooperation between the researchers and the involved authorities.

\footnotetext{
Authors' contributions

SB did the data collection and analysis, interpreted the data, provided the study results for writing the manuscript, drafted the work and substantively revised it. TP provided some research funding under the Research Program of Municipal Solid Waste and Hazardous Waste Management, Center of Excellence on Hazardous Substance Management (HSM), the S\&T Postgraduate Education and Research Development Office (PERDO), the Office of Higher Education Commission (OHEC), set up and designed the plan for this study, and approved all contents presented in the manuscript. WS partially provided some research grant from the Ratchadaphiseksomphot Endowment Fund (GCURS-59-06-79-01) for this study, and contributed to the conception. All authors read and approved the final manuscript.
}

\section{Funding}

This research was financially supported by the Grant for International Research Integration: Chula Research Scholar, Ratchadaphiseksomphot Endowment Fund (GCURS-59-06-79-01) and the Research Program of Municipal Solid Waste and Hazardous Waste Management, Center of Excellence on Hazardous Substance Management (HSM), the S\&T Postgraduate Education and Research Development Office (PERDO), the Office of Higher Education Commission (OHEC).

\section{Availability of data and materials}

Not applicable. The data will not be shared because all data displayed in the manuscript is sufficient to make readers understand.

\section{Competing interests}

The authors declare that they have no competing interests.

\section{Author details}

${ }^{1}$ International Program in Hazardous Substance and Environmental Management, Graduated School, Chulalongkorn University, Bangkok 10330, Thailand. ${ }^{2}$ Department of Environmental Science, Faculty of Science, Chulalongkorn University, Bangkok 10330, Thailand. ${ }^{3}$ Research Program of Municipal Solid Waste and Hazardous Waste Management, Center of Excellence on Hazardous Substance Management, Bangkok 10330, Thailand. ${ }^{4}$ College of Public Health Sciences, Chulalongkorn University, Bangkok 10330, Thailand.

Received: 31 March 2019 Accepted: 24 September 2019 Published online: 16 October 2019

\section{References}

1. PCD. Thailand state of pollution report 2015. Bangkok: Pollution Control Department; 2016

2. PCD. Thailand state of pollution report 2014. Bangkok: Pollution Control Department; 2015.

3. Thongkaow P, Prueksasit T, Siriwong W. Material flow of informal electronic waste dismantling in rural area of northeastern Thailand. Osaka: International Conference on Natural Science and Environment; 2017 Dec. p. 8-9.

4. Grant K, Goldizen FC, Sly PD, Brune MN, Neira M, van den Berg M, et al. Health consequences of exposure to e-waste: a systematic review. Lancet Glob Health. 2013;1:350-61.

5. Magalini F. Global challenges for e-waste management: the societal implications. Rev Environ Health. 2016;31:137-40.

6. Cobbing M. Toxic tech: not in our backyard - uncovering the hidden flows of e-waste. Amsterdam: Greenpeace International; 2008.

7. Robinson $\mathrm{BH}$. E-waste: an assessment of global production and environmental impacts. Sci Total Environ. 2009;408:183-91.

8. Zheng XB, Xu XJ, Yekeen TA, Zhang YL, Chen AM, Kim SS, et al. Ambient air heavy metals in $\mathrm{PM}_{2.5}$ and potential human health risk assessment in an informal electronic-waste recycling site of China. Aerosol Air Qual Res. 2016; 16:388-97.

9. Gangwar C, Choudhari R, Chauhan A, Kumar A, Singh A, Tripathi A. Assessment of air pollution caused by illegal e-waste burning to evaluate the human health risk. Environ Int. 2019;125:191-9.

10. Puangprasert S. Inhalation exposure to heavy metals and health risk assessment of separating electronic waste workers in Buriram Province [Bachelor's senior project]. Bangkok: Chulalongkorn University; 2015. [in Thai]

11. SKC. Operating instructions. SKC PMI samplers. Eighty Four: SKC Inc; 2019.

12. EPA US. Region III fact sheet. Quality control tools: blanks. Washington, DC: U.S. Environmental Protection Agency; 2009.

13. U.S. EPA. Air quality criteria for particulate matter. Washington, DC: U.S. Environmental Protection Agency, EPA/600/P-99/002aF; 2004.

14. Gu ZP, Feng JL, Han WL, Wu MH, Fu JM, Sheng GY. Characteristics of organic matter in $\mathrm{PM}_{2.5}$ from an e-waste dismantling area in Taizhou, China. Chemosphere. 2010;80:800-6.

15. Fang $W X$, Yang $Y C_{1}, X u Z M$. $P M_{10}$ and $P_{2.5}$ and health risk assessment for heavy metals in a typical factory for cathode ray tube television recycling. Environ Sci Technol. 2013:47:12469-76.

16. Zhang M. Air pollution and human health risk assessment in e-waste recycling sites and urban indoor environment in South China. Open Access Theses Dissert. 2017;463:55-7. 
17. Ogundele LT, Owoade OK, Olise FS, Hopke PK. Source identification and apportionment of $\mathrm{PM}_{2.5}$ and $\mathrm{PM}_{2.5-10}$ in iron and steel scrap smelting factory environment using PMF, PCFA and UNMIX receptor models. Environ Monit Assess. 2016;188:574.

18. EPA US. Overview of particle air pollution $\left(\mathrm{PM}_{2.5}\right.$ and $\left.\mathrm{PM}_{10}\right)$. Washington, $\mathrm{DC}$ : U.S. Environmental Protection Agency; 2012.

19. AQEG. Fine particulate matter $\left(\mathrm{PM}_{2.5}\right)$ in the United Kingdom. London: Air Quality Expert Group; 2012

\section{Publisher's Note}

Springer Nature remains neutral with regard to jurisdictional claims in published maps and institutional affiliations.

Ready to submit your research? Choose BMC and benefit from:

- fast, convenient online submission

- thorough peer review by experienced researchers in your field

- rapid publication on acceptance

- support for research data, including large and complex data types

- gold Open Access which fosters wider collaboration and increased citations

- maximum visibility for your research: over $100 \mathrm{M}$ website views per year

At $\mathrm{BMC}$, research is always in progress.

Learn more biomedcentral.com/submissions 